\title{
EFFECT OF WATERGYM IN KNEE OSTEOARTHRITIS
}

\author{
João Paulo Fernandes Guerreiro ${ }^{1}$, Renan Floret Turin $C_{l a r o}{ }^{1}$, João Daniel Rodrigues ${ }^{1}$, Beatriz Funayama Alvarenga Freire $^{1}$
}

\begin{abstract}
Objective: Evaluate the effectiveness of watergym to alleviate knee osteoarthritis $(\mathrm{OA})$ symptoms and improve locomotor function. Methods: Forty-two volunteers, 38 women and four men with $\mathrm{OA}$, practicing watergym, divided into the following groups: beginners, intermediate, advanced, and advanced level with other physical activities in addition to watergym were included in the study. Individuals were assessed at times zero, 8 and 12 weeks, with classes lasting 45 minutes, twice a week. Function was assessed by the Aggregate Locomotor Function (ALF) score, and pain and other symptoms by the visual analogical
\end{abstract}

scale (VAS) and by the Western Ontario and McMaster Universities Osteoarthritis Index (WOMAC) questionnaire. Statistical analysis was carried out by the variance analysis for repeated measurements, followed by Tukey's method for comparison of time point means whenever required. Results: None of the tests showed a significant improvement of pain or locomotion. Conclusion: Watergym was not effective in improving symptoms and did not affect the locomotor capacity of individuals with knee OA. Level of evidence IV, Case series.

Keywords: Hydrotherapy. Osteoarthritis. Knee. Motor Activity.

Citation: Guerreiro JPF, Claro RFT, Rodrigues JD, Freire BFA. Effect of watergym in knee osteoarthritis. Acta Ortop Bras. [online]. 2014;22(1):25-8. Available from URL: http:// www.scielo.br/aob.

\section{INTRODUCTION}

Osteoarthritis $(\mathrm{OA})$ is the most common rheumatic disease. It affects about one fifth of the world population and it is considered one of the most frequent causes of work incapacity after the age of $50 .{ }^{1}$ Being characterized by the degeneration of articular cartilage, OA may be asymptomatic or can manifest with mechanical type pain, protokinetic stiffness and may eventually present inexpressive joint inflammatory signals. It affects predominantly adult females between the $4^{\text {th }}$ and $5^{\text {th }}$ decades of life and during menopause, mainly affecting the joints of the hips, knees, hands and spine. ${ }^{2,3}$ Knee OA can be detected by $X$-ray in $52 \%$ of the adult population and it is the form most commonly found in obese women. ${ }^{4}$

Treatment of OA focuses on clinical, functional and mechanical joints improvement. The approach must be multidisciplinary and rely on pharmacological and non- pharmacological measures. Therapeutic exercises and sports activities guided by a qualified professional should be prescribed and encouraged. ${ }^{5,6}$ Physical activity is recommended for patients with knee OA as one of the most effective non-pharmacological therapies and may improve range of motion, stiffness, pain and quality of life. ${ }^{7,8}$ Among the activities listed, the exercises in the water, in form of hydrotherapy shown to be effective in controlling pain and function such as walking and climbing stairs. ${ }^{9}$ in patients with $\mathrm{OA}$, hydrotherapy has been extensively studied and a re- cent systematic review ${ }^{10}$ showed that few studies were high quality or adequate to reveal its effects . However, moderate improvement can be evidenced in function, pain and quality of life of patients with knee OA through aquatic exercise.

Hydrogym is a gym modality practiced in pools that is widely spread as a low impact sports practice that provides muscle strengthening. ${ }^{11}$ Offered in clubs and gym academies in the form of guided and supervised by physical educators, water aerobics classes is practiced in large groups and the exercises are standardized. On the other hand, hydrotherapy is prescribed as part of the treatment for patients with $\mathrm{OA}$ and, therefore, oriented according to the specific needs and constraints of each individual. The sessions are run by physiotherapist and occur singly or in small groups.

Reports showing the effectiveness of aerobics in patients with $\mathrm{OA}$ are scarce. Thus, the aim of this study was to evaluate whether the practice of watergym, on the modalities offered at sports clubs and gym academies can benefit patients with knee OA, on the improvement of pain symptoms and the locomotor function.

\section{METHODS}

The project was approved by the Ethics Research Committee of the Faculdade de Medicina de Botucatu-Unesp, all volunteers in the study were previously informed about the experiment and signed informed consent forms. All individuals attending

All the authors declare that there is no potential conflict of interest referring to this article.

\footnotetext{
1. Faculdade de Medicina de Botucatu, Universidade Estadual Paulista Júlio Mesquita Filho-Unesp, Botucatu, SP, Brazil.

Research performed at the Rheumatology Service and the Department of Clinical Medicine, Faculdade de Medicina de Botucatu, Universidade Estadual Paulista Júlio Mesquita Filho. Unesp, Botucatu, SP, Brazil

Correspondence: Rubião Jr. s/n, Caixa postal 571.Botucatu, SP, Brazil. 18618-000. joaoguerreiro39@yahoo.com.br
} 
water aerobics classes, and those who were about to start, were invited to attend. The selection criteria were that they were over 50 years old and had a history of at least one episode of pain in one or both knees in the past 30 days. All underwent clinical evaluation by a rheumatologist or orthopedist for the diagnosis of knee osteoarthritis. Those who met the criteria for classification of knee OA of the American College of Rheumatology (ACR) were included..$^{12}$ Practitioners who had experienced any musculoskeletal and/or joint infiltration in 3 months prior to the surgery were excluded. The use, if necessary, of analgesics and/or non-steroidal oral anti-inflammatories was allowed.

\section{Procedures}

Clinical and functional evaluations were performed at start, after eight and after 12 weeks of watergym practice. Water aerobics classes occurred at a $1.40 \mathrm{~m}$ depth pool heated to $32^{\circ} \mathrm{C}$ during 45 minutes, twice a week, divided into five moments in the following sequence: warming up, stretching, aerobic exercises, stretching and relaxing. Aerobic exercises include running, tripping, displacement, and localized exercises for upper and lower limbs and trunk.

Locomotor function was assessed by the aggregate score of aggregator locomotor function (ALF), which comprises the sum of necessary times required to perform the following activities: walking up and down stairs and move to and from a chair. ${ }^{13}$ Walking: the participant was asked to walk in its natural and comfortable pace through a $10 \mathrm{~m}$ distance. Time was measured during the central $8 \mathrm{~m}$ to eliminate the first and last steps of the beginning and end of the route used for acceleration and deceleration respectively, increasing the reliability of the test. For each participant, three time measurements were performed and considered their mean value.

Climbing and descending stairs: the participant was asked to climb and descend seven steps in his/her natural and comfortable pace. The use of handrails was allowed if the participant considered necessary. It was registered if the participant used the legs alternately, the handrail or always the same leg. Four replicates were performed and the average time was considered for analysis.

Transfer from and to a chair: the participant was asked to walk in his/her natural and comfortable pace a $2 \mathrm{~m}$ distance towards a chair and sit down, immediately get up and return to the starting point. An armless chair was used. Three repetitions were performed and the average time was considered.

The subjective rating of pain, stiffness, physical function and quantification of painful symptoms was performed using the WOMAC index ${ }^{14}$ and the visual analog scale (VAS) respectively, considering only the knee joints.

Subjects were divided according to the time of actual practice of physical activity. Thus, three groups were identified: beginners, intermediate and advanced. Beginners were those who did not practice any physical activity and started with watergym at enrollment or who practiced for a period less than eight weeks. Intermediates were those who practiced watergym effectively for a period of at least eight weeks and no longer than six months. Practitioners over six months of effective practice were considered advanced. Other physical activities and the participant's motivation in watergym practice were also reported.

\section{Statistical Analysis}

For ALF, WOMAC and VAS variables, a model with repeated measurements was adjusted, considering the groups and moments as main effects and the interaction group $x$ moments. The analysis was performed using the PROC MIXED procedure of SAS for Windows, v.9.1.3, which takes into account correlations between times. The Tukey test adjusted for the present model was carried out for the interaction group $x$ time, in order to check the differences between groups by setting the time and vice versa (moment fixing group). The level of significance was 5\%.

To study the motivation of individuals, the chi-square test was used. ${ }^{15}$

\section{RESULTS}

Ninety-nine subjects volunteered and passed through medical assessment. None of them underwent any surgery or intra-joint injections. Eight of them were excluded for not meeting the classification criteria for OA. Forty-nine went through the first assessment and were, however, later deleted. The reason for exclusion was that they did not attended further assessments or being evaluated in sessions not established by the study protocol or because they stopped to practice exercises or were absent in more than $20 \%$ of classes. One patient died of causes unrelated to the study. Thus, the sample loss was $53.84 \%$. (Figure 1)

The reasons that led these individuals to seek practice exercises were: 27 (27.2\%) to do some sort of physical activity; 19 (19.1\%) through medical indication; twelve (12.1\%) for social interaction; seven (7.07\%) for fitness; four (4.04\%) had other reasons, two (2.02\%) did not answer the question and $14(14.1 \%)$ had more than one reason. (Figure 2)

Forty-two participants were considered valid for the study. Of these, eight were considered beginners and other eight intermediaries. None of these 16 individuals practiced any physical activity other than watergym. In the advanced stage, 26 individuals were identified, ten of them were sedentary when starting watergym, this being the only physical activity they practiced, 16 practiced other physical activities besides watergym. The reported activities were: regular daily walks $(n=9)$, gymnastics $(n=3)$, resistance exercises with weights $(n=2)$, swimming $(n=2)$, soccer $(n=1)$ and more than one activity $(n=3)$. Six of these individuals participated in various scheduled weekly activities since they participated in physical activity for seniors groups.

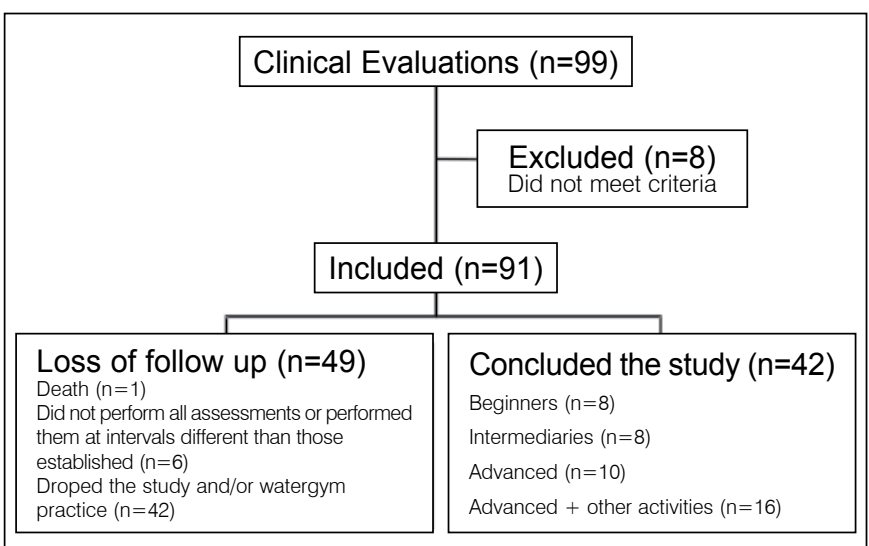

Figure 1. Flow of study participants through selection and intervention. 


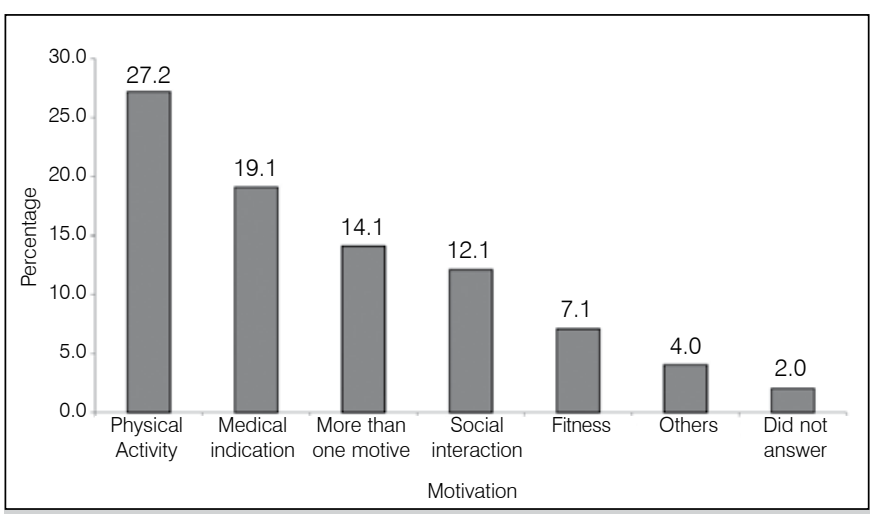

Figure 2. Percentage of individuals according to motivation for watergym practice.

The mean age of all participants included was $59.35 \pm 6.55$ years old. In the novice group it was $63.5 \pm 4.92(70-57)$ years old, in the intermediate group 57.6 \pm 6.98 (68-50) years old; in the advanced group that was initially sedentary $57.2 \pm 6.01$ (68-50) years old and the advanced group who practiced other activities it was $59.5 \pm 6.89$ (73-50) years old.

The predominant gender was female with 38 (90.4\%) participants and only four male participants (99.5\%). The results were presented as mean and standard deviation for each group and the three assessments occurred during the study. (Table 1)

The results obtained in the ALF score, quantification of pain by VAS and WOMAC were presented by mean and standard deviation for the three moments. (Tables 1,2 and 3)

The comparison of the moments in each group and the means of the groups at each moment for the different evaluations, ALF score, VAS and WOMAC showed no statistically significant difference $(P \leq 0.05)$.

If we use the international criteria in the assessment of pain by VAS, in which a drop of $20 \mathrm{~mm}$ in this index can be considered therapeutic response in OA, then six subjects obtained it. ${ }^{16}$ They are, however, spread the over groups: one at the beginner's group, two at the intermediate, two at the advanced and one in the advanced group with other activities.

Table 1. Mean and Standard Deviation regarding VAS according to moment and group.

\begin{tabular}{c|c|c|c}
\hline \multirow{2}{*}{ Group } & \multicolumn{3}{|c}{ Moment } \\
\cline { 2 - 4 } & Initial & 8 weeks & 12 weeks \\
\hline Beginners & $25.8 \pm 7.3$ & $21.6 \pm 3.3$ & $22.4 \pm 4.7$ \\
\hline Intermediaries & $22.0 \pm 4.6$ & $23.4 \pm 5.0$ & $23.1 \pm 5.1$ \\
\hline Advanced & $29.5 \pm 8.5$ & $27.4 \pm 6.9$ & $27.0 \pm 6.8$ \\
\hline Advanced + other activities & $20.2 \pm 3.4$ & $19.8 \pm 2.9$ & $20.0 \pm 3.6$ \\
\hline
\end{tabular}

Table 2. Mean and Standard Deviation regarding VAS according to moment and group

\begin{tabular}{c|c|c|c}
\hline \multirow{2}{*}{ Group } & \multicolumn{3}{|c}{ Moment } \\
\cline { 2 - 4 } & Initial & 8 weeks & 12 weeks \\
\hline Beginners & $35.0 \pm 27.2$ & $27.7 \pm 26.5$ & $32.3 \pm 21.6$ \\
\hline Intermediaries & $58.8 \pm 9.5$ & $30.0 \pm 29.4$ & $25.5 \pm 33.3$ \\
\hline Advanced & $33.3 \pm 27.8$ & $32.5 \pm 22.3$ & $32.8 \pm 22.8$ \\
\hline Advanced + other activities & $39.9 \pm 24.4$ & $40.0 \pm 21.7$ & $39.3 \pm 27.4$ \\
\hline
\end{tabular}

Table 3. Mean and Standard Deviation regarding WOMAC according to moment and group.

\begin{tabular}{c|c|c|c}
\hline \multirow{2}{*}{ Group } & \multicolumn{3}{|c}{ Moment } \\
\cline { 2 - 4 } & Initial & 8 weeks & 12 weeks \\
\hline Beginners & $72.7 \pm 13.2$ & $73.8 \pm 6.5$ & $73.1 \pm 11.1$ \\
\hline Intermediaries & $69.0 \pm 15.5$ & $75.0 \pm 17.3$ & $79.5 \pm 17.4$ \\
\hline Advanced & $71.7 \pm 10.0$ & $75.3 \pm 9.6$ & $70.7 \pm 10.3$ \\
\hline Advanced + other activities & $71.7 \pm 15.3$ & $78.1 \pm 12.4$ & $77.4 \pm 14.7$ \\
\hline
\end{tabular}

\section{DISCUSSION}

Water aerobics are a common practice nowadays, in gyms and sports clubs. Many of their attendants are attracted by the possible beneficial effects on their health and that would not cause the problems that impact due to activities in soil could cause to the joints. In water, even in the case of resistance exercises, there would be the same amount of cargo. This idea is present both among laity and medical professionals. In this study $27.2 \%$ of individuals sought in watergym a way to maintain regular physical activity. However, $19.1 \%$ of subjects started gymnastics by medical prescription in order to relieve joint pain or as a way to improve the overall physical condition. Exercising in water, as swimming or watergym is the second most prescribed sports modality by Brazilian orthopedic, only behind gait. ${ }^{17}$ It is interesting noting that $12.1 \%$ of the practitioners began to attend the pool for social interaction, what, since ancient times, is a motivation for thermal therapy. However, none reported that medical indication aimed to improve the psychosocial status. The number of individuals who began their physical activity as watergym classes and twelve weeks later abandoned it was very high. Of the 91 individuals who were included in the study, 49 subjects did not continue the exercise program or did not practice frequently at the minimum intensity required by the protocol. The causes for this high number of dropouts, includes the barriers identified in previous studies ${ }^{18}$ such as lack of time, insecurity and limited mobility, presence of chronic diseases, lack of ability, changes in climate and the lack of information about the real benefits of regular physical activity, the concepts that physical activity is something strenuous and uncomfortable. Women were identified as those who most reported symptoms and climatic barriers when compared to men. In our study, more than $90 \%$ of practitioners were females.

Functional evaluation of the knees, through the ALF score, and subjective assessment of pain, stiffness, physical function, and painful symptoms through the WOMAC questionnaire showed no improvement or significant change in both groups when compared with different levels of effective practice of watergym as compared individual scores of each subject in the three assessments conducted during the twelve weeks. These results were also found in other studies evaluating joint function and painful symptoms. ${ }^{10} \mathrm{~A}$ Systematic review of the effect of aquatic exercise in the treatment of knee and hip OA revealed that only six published studies that included a total of 800 participants were adequately designed to assess such effects. ${ }^{10}$ Of these, only one work included patients who presented isolated affected knees. This study compared aquatic exercises with exercises performed in soil and found improvement of pain immediately after treatment and no evidence was found in stiffness and ability to walk. ${ }^{19}$ Silva et al. ${ }^{20}$ found significant improvement 
in pain and WOMAC scores of patients with knee OA undergoing exercise in water and soil, with follow-up of 18 weeks. There was significantly greater improvement in the condition of patients who performed exercises in the water. The activities were developed in groups of a maximum of eight participants, by two physiotherapists aware of the purposes of the study. Aquatic exercises in the form of hydrotherapy and watergym classes in sports clubs and gyms have fundamental differences. The first is therapeutic, individualized, targeted and oriented towards each patient and supervised by a professional physiotherapist. The second has a sporty character, it is practiced in large groups, often without adequate supervision, with standardized classes for the group regardless the possible limitations that individuals may have.
It should also be emphasized that in the present study, other possible benefits that the practice of watergym may bring to its practitioners than pain and function in knee OA, have not been evaluated.

\section{CONCLUSION}

The practice of watergym, as it is found in gyms and sports clubs, was not effective in reducing pain and function in knee OA after 12 weeks assessment.

\section{ACKNOWLEDGEMENTS}

The authors wish to thank Prof. Dr. Lydia Raquel de Carvalho, Department of Statistics, Instituto de Biociências, UNESP, for statistical analysis.

\section{REFERENCES}

1. Sharma L, Kapoor D, Issa S. Epidemiology of osteoarthritis: an update. Curr Opin Rheumatol. 2006;18(2):147-56.

2. Mankin HJ, Brandt KD. Pathogenesis of osteoarthritis. In: Kelley WN, Harris ED, Ruddy S, Sledge CB. Textbook of rheumatology. 5a ed. Philadelphia: Saunders; 1997. p.1369-82.

3. Mello SBV, Laurindo IMM. Osteoartrose. In: Yoshinari NH, Bonfá ESDO. Reumatologia para o clínico. São Paulo: Rocca. 2000. p.139-48.

4. Martin DF. Pathomechanics of knee osteoarthritis. Med Sci Sports Exerc. 1994; 26(12):1429-34.

5. Coimbra IB, Pastor, EH, Greve JMA, Puccinelli MLC, Fuller R, Cavalcanti FS, et al. Brazilian consensus for treatment of osteoarthritis. Rev Bras Reumatol. 2002;42(6):371-4.

6. Zhang W, Moskowitz RW, Nuki G, Abramson S, Altman RD, Arden N, et al. OARSI recommendations for the management of hip and knee osteoarthritis, Part II: OARSI evidence-based, expert consensus guidelines. Osteoarthritis Cartilage. 2008;16(2):137-62.

7. Resnick B. Managing arthritis with exercise. Geriatr Nurs. 2001;22(3):143-50.

8. Roddy E, Zhang W, Doherty M, Arden NK, Barlow J, Birrell F, et al. Evidence-based recommendations for the role of exercise in the management of osteoarthritis of the hip or knee--the MOVE consensus. Rheumatology (Oxford). 2005;44(1):67-73.

9. Foley A, Halbert J, Hewitt T, Crotty M. Does hydrotherapy improve strength and physical function in patients with osteoarthritis--a randomised controlled trial comparing a gym based and a hydrotherapy based strengthening programme. Ann Rheum Dis. 2003;62(12):1162-7.

10. Bartels EM, Lund H, Hagen KB, Dagfinrud H, Christensen R, Danneskiold-Samsøe B. Aquatic exercise for the treatment of knee and hip osteoarthritis. Cochrane Database Syst Rev. 2007;(4):CD005523.

11. Rochan JCC .Hidroginástica teoria e prática. 4a ed. Rio de Janeiro: Sprint; 2001.
12. Altman R, Asch E, Bloch D, Bole G, Borenstein D, Brandt K, et al. Development of criteria for the classification and reporting of osteoarthritis. Classification of osteoarthritis of the knee. Diagnostic and Therapeutic Criteria Committee of the American Rheumatism Association. Arthritis Rheum. 1986;29(8):1039-49.

13. McCarthy CJ, Oldham JA. The reliability, validity and responsiveness of anaggregated locomotor function (ALF) score in patients with osteoarthritis of the knee. Rheumatology (Oxford). 2004;43(4):514-7.

14. Fernandes, MI, Ferraz, MB, Ciconelli, RM . Tradução e Validação do Questionário de Qualidade de Vida Específico para Osteoartrose (WOMAC) para a Língua Portuguesa. Rev Paul Reumatol. 2003;10:25.

15. Fisher LD. Biostatistics - a methodology for the health sciences. New York: John Wiley; 1993.

16. Pham T, van der Heijde D, Altman RD, Anderson JJ, Bellamy N, Hochberg M, et al. OMERACT-OARSI initiative: Osteoarthritis Research Society International set of responder criteria for osteoarthritis clinical trials revisited. Osteoarthritis Cartilage. 2004;12(5):389-99.

17. Seixas MA, Matsudo SMM, Matsudo VKR, Andrade EL, Braggion GF. Padrão da prescrição de atividade física realizada por médicos ortopedistas brasileiros. Rev Bras Cienc Mov. 2003;11(2):63-9.

18. Brawley LR, Rejeski WJ, King AC. Promoting physical activity for older adults: the challenges for changing behavior. Am J Prev Med. 2003;25(3 Suppl 2):172-83.

19. Wyatt FB, Milam S, Manske RC, Deere R. The effects of aquatic and traditional exercise programs on persons with knee osteoarthritis. J Strength Cond Res. 2001;15(3):337-40.

20. Silva LE, Valim V, Pessanha AP, Oliveira LM, Myamoto S, Jones A, et al. Hydrotherapy versus conventional land-based exercise for the management of patients with osteoarthritis of the knee: a randomized clinical trial. Phys Ther. 2008;88(1):12-21. 